Reprinted from:

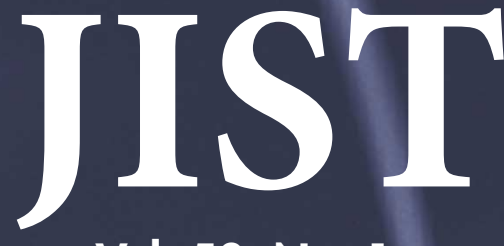

Vol. 53, No. 1 January/February 2009
Journal of

Imaging Science and Technology

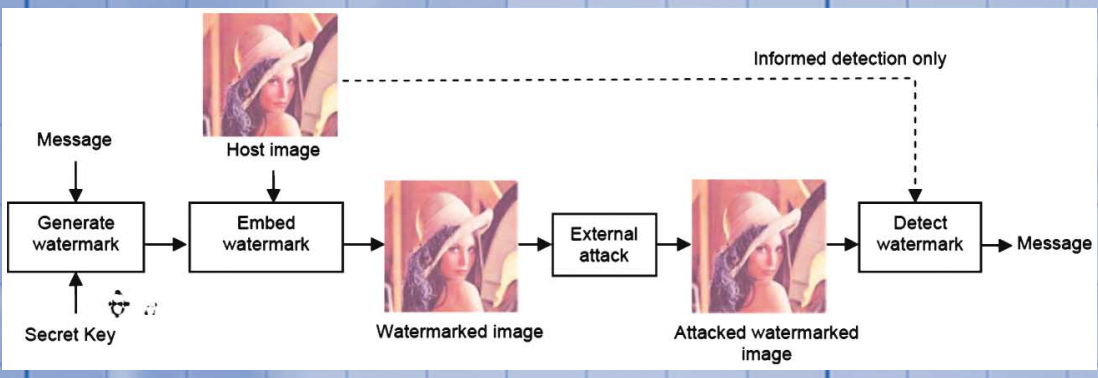





\title{
Electrical and Thermal Properties of Azo-Metal Complexes used as Charge-Control Agents
}

\author{
Y. Sato, S. Ito, K. Uta and J. Mizuguchi ${ }^{-}$ \\ Graduate School of Engineering, Yokohama National University, 79-5 Tokiwadai, Hodogaya-ku, \\ 240-8501 Yokohama, Japan \\ E-mail:mizu-j@ynu.ac.jp
}

\begin{abstract}
The authors have recently proposed a novel chargecontrol mechanism that assumes an appreciable temperature increase at the "toner/carrier" interface due to the triboelectrification. In this model, the temperature dependence of the electrical conductivity of charge-control agents (CCAs) plays the crucial role. Therefore, electrical and thermal properties of azo-metal complexes used as CCAs have been investigated in order to provide additional evidence for our model as well as to study their high thermal stability. The electrical conductivity of a typical azo-Fe complex (i.e., T-77 from Hodogaya Chemical) is found to increase exponentially with temperature, and the value around $100^{\circ} \mathrm{C}$ is about two to three orders of magnitude higher than that at room temperature. This supports our charge-control mechanism. On the other hand, the structure analyses of $T-77$, sodium salt of $T-77$, and sodium salt of a Cr-complex revealed that there are intermolecular hydrogen-bond networks or coordination networks, in which each cation bridges neighboring anions. This type of network is found to be responsible for high thermal stability above $250^{\circ} \mathrm{C}$. (๑) 2009 Society for Imaging Science and Technology.
\end{abstract}

[DOI: 10.2352/J.ImagingSci.Technol.(2009)53:1(010504)]

\section{INTRODUCTION}

Azo-metal complexes are well-known classical colorants as characterized by the azo group $(-\mathrm{N}=\mathrm{N}-) .{ }^{1}$ Nowadays, fewer metal complexes are used in the textile industry because of environmental and ecological problems. On the other hand, metal-complex dyes find application as powerful charge-control agents (CCAs) for toners to create a desired charge level and polarity. As for the charge-control mechanism, a number of investigations have been carried out on the basis of the effective electric field, ${ }^{2,3}$ work function, ${ }^{4}$ mass transfer, ${ }^{5}$ and charge transfer. ${ }^{6}$ However, no clear-cut, consistent explanation has yet been established. In view of the present situation, we have recently proposed a novel model that assumes an appreciable temperature increase at the "toner/carrier" interface due to the triboelectrification (Figure 1). ${ }^{7}$ Because of this instantaneous local heating, the electrical conductivity of the CCA (which resides on the surface of both toner and carrier) is significantly increased to provide a conductive channel, through which the carrier flow effectively occurs to charge the toner. These two as-

\section{IS\&T Member.}

Received May 5, 2008; accepted for publication Oct. 28, 2008; published online Feb. 5, 2009

$1062-3701 / 2009 / 53(1) / 010504 / 9 / \$ 20.00$. sumptions have been experimentally verified. ${ }^{7}$ Especially, local heating up to ca. $100^{\circ} \mathrm{C}$ has been confirmed using a pigment marker (ethylpyridylperyleneimide ${ }^{8}$ ) that changes its color from black (trans-form) to red (cis-form). Around this temperature, the electrical conductivity of CCA increases remarkably by two to three orders of magnitude compared with that at room temperature.

The purpose of the present investigation is twofold. The first objective is to provide more experimental evidence for our charge-control mechanism by showing the temperature dependence of the electrical conductivity of a typical azo-Fe complex used in practice as a CCA of the negative type (product name: T-77 from Hodogaya Chemical: Figure 2). Secondarily, we intend to structurally clarify why T-77 is so thermally stable, although it is inherently only an ammonium salt. High thermal stability is a prerequisite for CCAs, because pulverized toners are usually prepared at about $130-180^{\circ} \mathrm{C}$ by kneading various toner components such as polymer, colorant, CCA, etc. Accordingly we found in T-77 the existence of strong intermolecular forces through $\mathrm{NH} \cdots \mathrm{O}$ hydrogen bonds between the $\mathrm{NH}$ group of one cation and the carbonyl $\mathrm{O}$ atom of the Fe-anion complex. It is this hydrogen-bond network that imparts a polymerlike stability to T-77. Furthermore, we have extended our study to different azo-metal salts (i.e., sodium salt of T-77, designated as $\mathrm{T}-77 \mathrm{Na}$ ) and sodium salt of a Cr-complex (designated as S-34Na: Figure 3) in order to generalize our theory of stability of azo-metal complexes.

The first part of the present paper deals with the electrical properties and the crystal structure of T-77. The

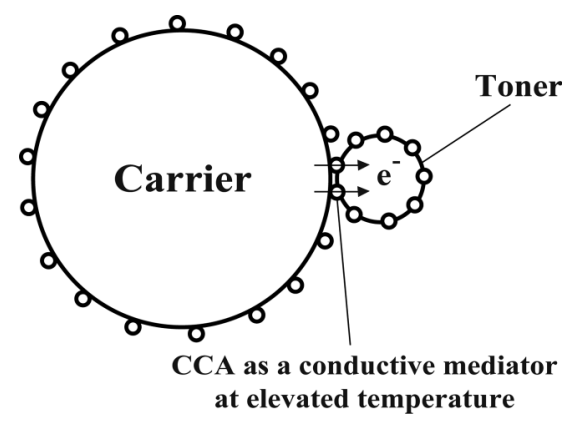

Figure 1. Toner charging through conductive channels formed at the "toner/carrier" interface in tribo-electrification. 


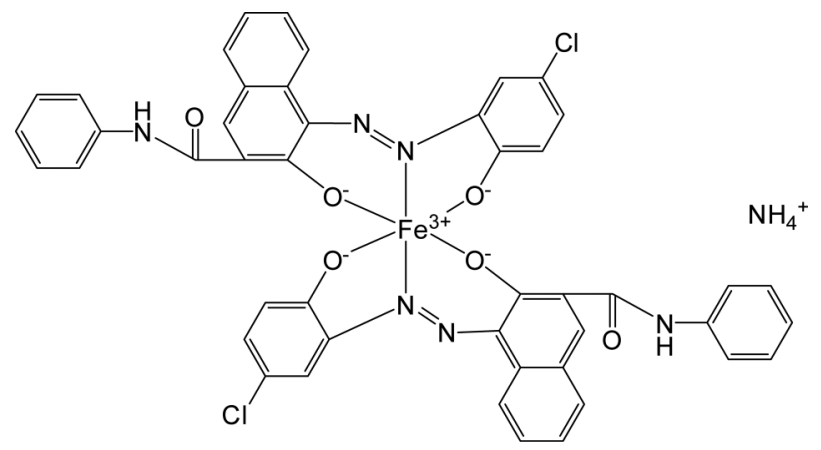

(a)

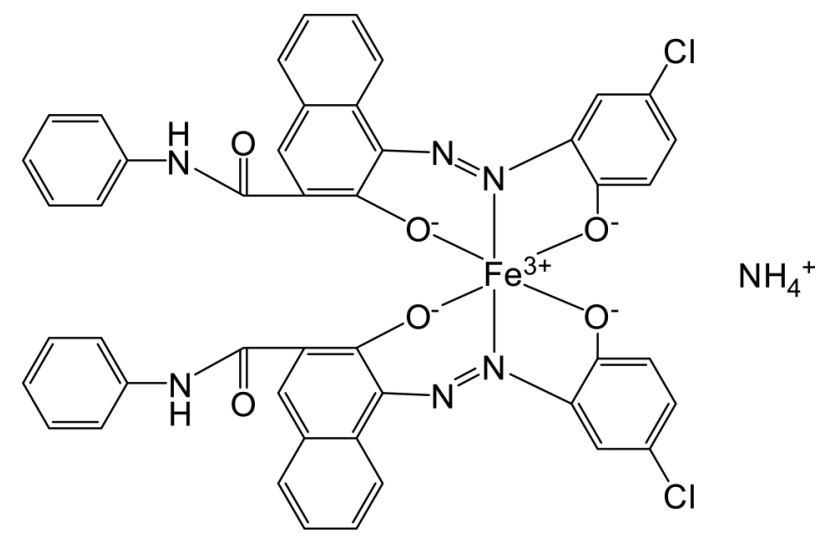

(b)

Figure 2. Molecular structure of T-77 (CAS No. 104815): (a) The structure presented usually in literature and (b) the structure determined by $x$-ray analysis (i.e., this work).

second part discusses the thermal stability of T-77Na and S-34Na on the basis of the crystal structure.

\section{EXPERIMENT}

\section{Preparation of Azo-Metal Complexes and their Crystal Growth}

T-77 (Hodogaya Chemical: CAS No. 104815) was synthesized according to the method reported in literature ${ }^{9}$ and purified three times by recrystallization from methanol. T-77Na was synthesized according to the method previously reported. ${ }^{10} \mathrm{~S}-34 \mathrm{Na}$ was obtained from Orient Chemical Industries, Ltd.

Single crystals of T-77 were grown by recrystallization from methanol or acetone in solution. After $48 \mathrm{~h}$, a number of black crystals were obtained in the form of platelets from a methanol solution (size: $0.20 \times 0.20 \times 0.10 \mathrm{~mm}^{3}$ ) and in the form of blocks from an acetone solution (size: $0.10 \times 0.10 \times 0.04 \mathrm{~mm}^{3}$ ). Both crystals were found to include one solvent molecule per molecule according to thermogravimetric analysis.

Similarly, single crystals of $\mathrm{T}-77 \mathrm{Na}$ were grown by recrystallization from an acetone or acetonitrile solution. After $48 \mathrm{~h}$, a number of black crystals were obtained in the form of blocks in both solvents. Single crystals of S-34Na were obtained by recrystallization from an acetone solution. After $48 \mathrm{~h}$, a number of black crystals were precipitated in the form of blocks.

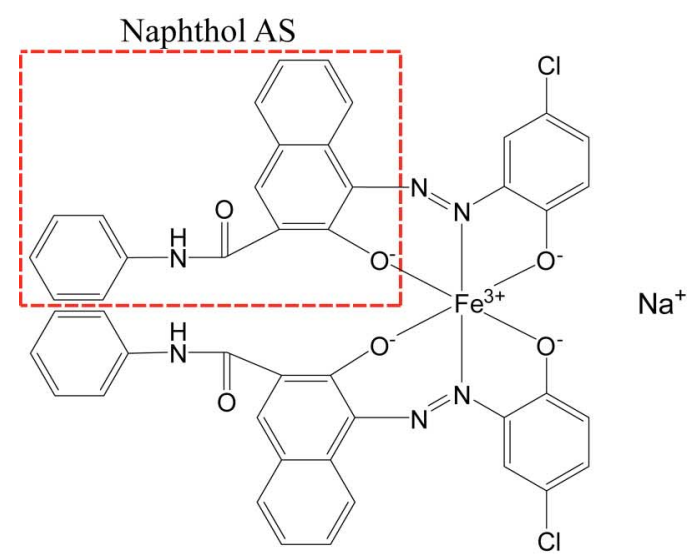

(a)

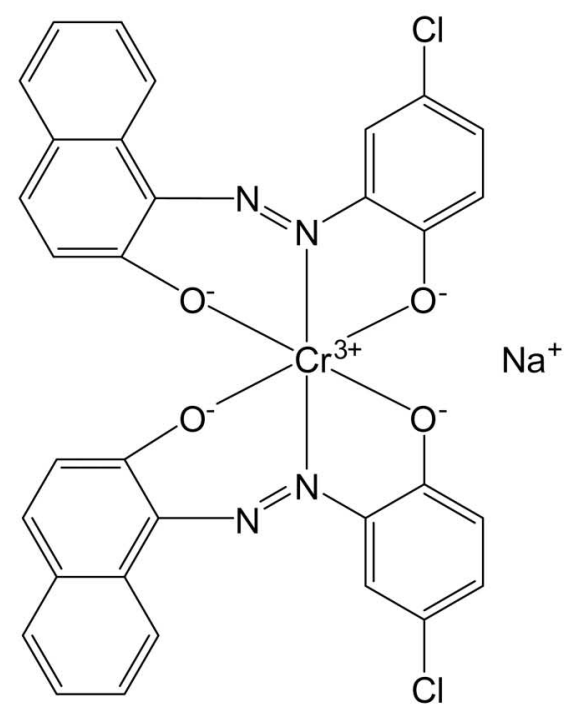

(b)

Figure 3. (a) Sodium salt of T-77 (i.e., T-77Na), which includes two naphthol AS moieties, and (b) sodium salt of an azo-Cr complex: S-34Na, where S-34 (with $\mathrm{H}^{+}$instead of $\mathrm{Na}^{+}$) is a commercial product of Orient Chemical Industries, Ltd. S-34Na lacks the moiety of naphthol AS.

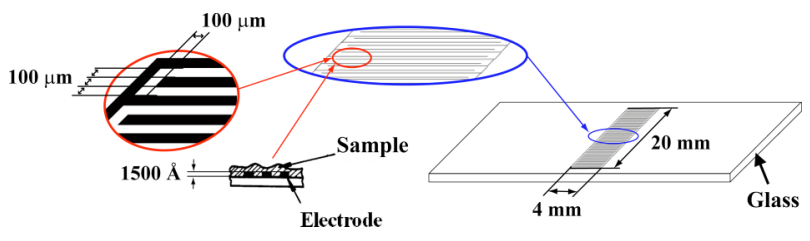

Figure 4. Interdigital electrodes made of indium-tin-oxide.

\section{Collection of Reflection Data and X-Ray Structure Analysis}

In all crystals of T-77, T-77Na, and S-34Na, reflection data were collected on an R-AXIS RAPID/F diffractometer from Rigaku using $\mathrm{MoK} \alpha$ radiation $(\lambda=0.71075 \AA)$ at $93 \mathrm{~K}$, since all single crystals are found to include solvent molecules. The structures of all crystals were solved by direct methods [SIR2004 ${ }^{11}$ ], and refinement was carried out by the full-matrix least-squares method on $F^{2}$ [SHELXL97 $\left.^{12}\right]$. 
Table I. Crystallographic parameters for T-77/methanol or T-77/acetone.

\begin{tabular}{|c|c|c|}
\hline & $\mathrm{T}-77 /$ methanol $^{13}$ & T-77/acetone ${ }^{14}$ \\
\hline Formula & $\begin{array}{c}\left(\mathrm{NH}_{4}\right)\left[\mathrm{Fe}\left(\mathrm{C}_{23} \mathrm{H}_{14}\left(\mathrm{IN}_{3} \mathrm{O}_{3}\right)_{2}\right]\right. \\
\left(\mathrm{CH}_{4} \mathrm{O}\right)\end{array}$ & $\begin{array}{c}\left(\mathrm{NH}_{4}\right)\left[\mathrm{Fe}\left(\mathrm{C}_{23} \mathrm{H}_{14} \mathrm{ClN}_{3} \mathrm{O}_{3}\right)_{2}\right] \\
\left(\mathrm{C}_{3} \mathrm{H}_{6} \mathrm{O}\right)\end{array}$ \\
\hline Crystal system & Tridlinic & Monodinic \\
\hline Space group & PI & $P 2_{1} / n$ \\
\hline Molecular weight & 937.58 & 963.62 \\
\hline$Z$ & 2 & 4 \\
\hline$a(\AA)$ & $10.1107(4)$ & $11.3199(14)$ \\
\hline$b(\AA)$ & $14.1645(6)$ & $13.7962(17)$ \\
\hline$c(\AA)$ & $15.3877(7)$ & 27.757(4) \\
\hline$\alpha\left({ }^{\circ}\right)$ & $103.2240(11)$ & 90.0000 \\
\hline$\beta\left({ }^{\circ}\right)$ & $102.8270(12)$ & $93.747(3)$ \\
\hline$\gamma\left({ }^{\circ}\right)$ & $94.0860(12)$ & 90.0000 \\
\hline Density $\left(\mathrm{g} / \mathrm{cm}^{3}\right)$ & 1.501 & 1.480 \\
\hline$R$ & 0.054 & 0.089 \\
\hline
\end{tabular}

Preparation of Samples for the Electrical Measurements Measurements of the electrical conductivity in the form of powders are often not very reproducible or reliable owing to variation in the packing density of the powder as well as to electroding problems. Therefore, thin layers of methanol or acetone-solvated crystals of T-77 were directly deposited on ITO (indium-tin-oxide) interdigital electrodes by spin coating (Figure 4).

\section{Measurements}

The temperature dependence of the electrical conductivity was measured with a 6514 Keithley electrometer in the temperature range between room temperature and $200^{\circ} \mathrm{C}$ at a heating rate of $3 \mathrm{~K} / \mathrm{min}$. Thermogravimetric analysis (TGA) and differential thermal analysis (DTA) were carried out in air at a heating rate of $10 \mathrm{~K} / \mathrm{min}$, using a Rigaku Thermo Plus TG-8120 instrument.

\section{RESULTS AND DISCUSSION}

First Part-Crystal Structure and Electrical Properties of $T-77$

Crystallographic parameters and molecular conformation of solvated T-77

Table I details the crystallographic parameters for methanol or acetone-solvated azo-Fe complexes and these are designated by T-77/methanol and T-77/acetone. ${ }^{13,14}$ It is interesting to note that the space group is different (i.e., molecular arrangement is different), depending on the solvent used: $P \overline{1}$ and $P 2_{1} / n$, respectively.

Figure 5 shows the ORTEP plot of T-77/methanol. The Fe anion complex has no crystallographic symmetry. Pairs of the equivalent ligands lie cis to each other, showing that the anion complex has no inversion symmetry and that the mo-

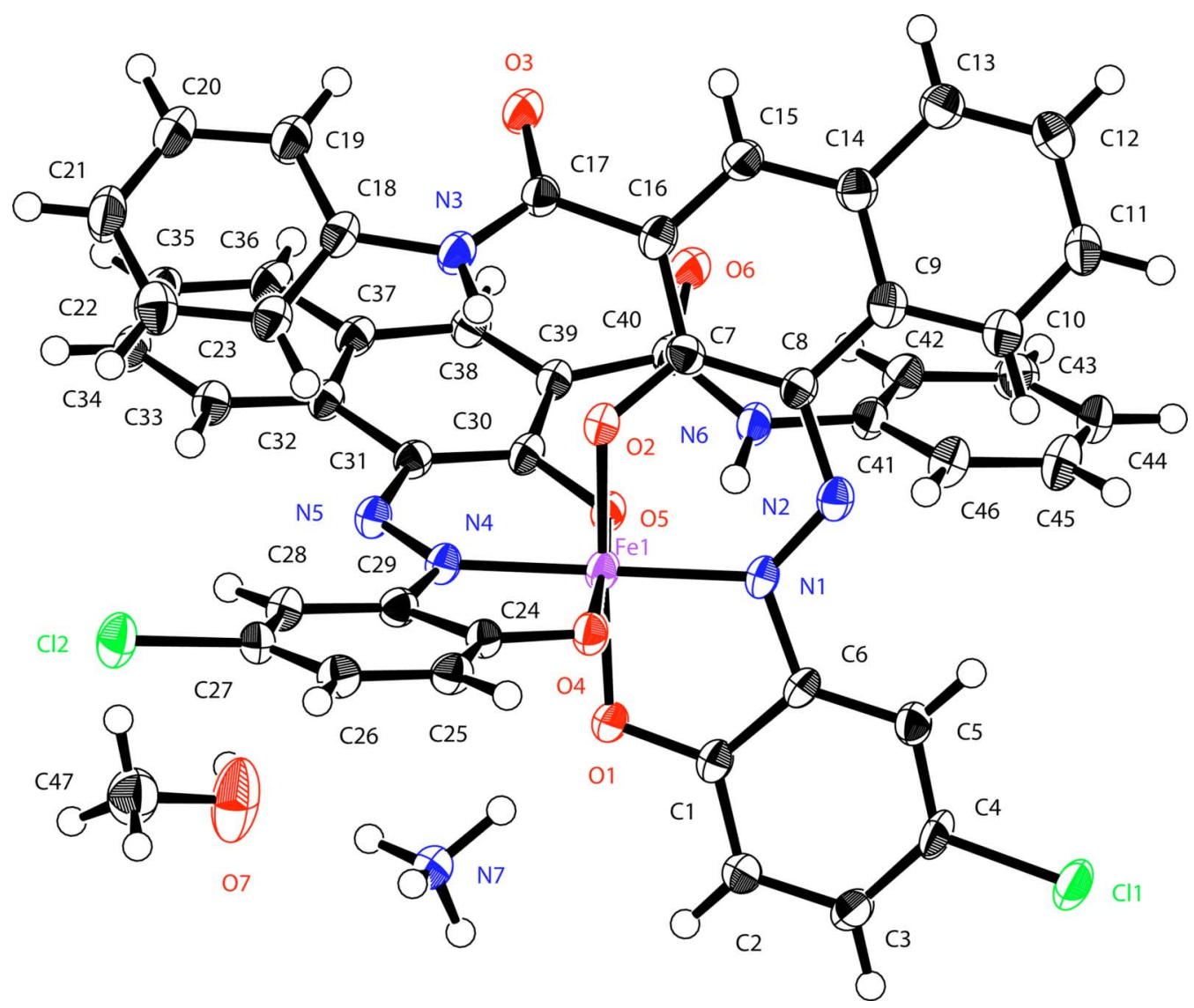

Figure 5. ORTEP plot of $\mathrm{T}-77 /$ methanol. 


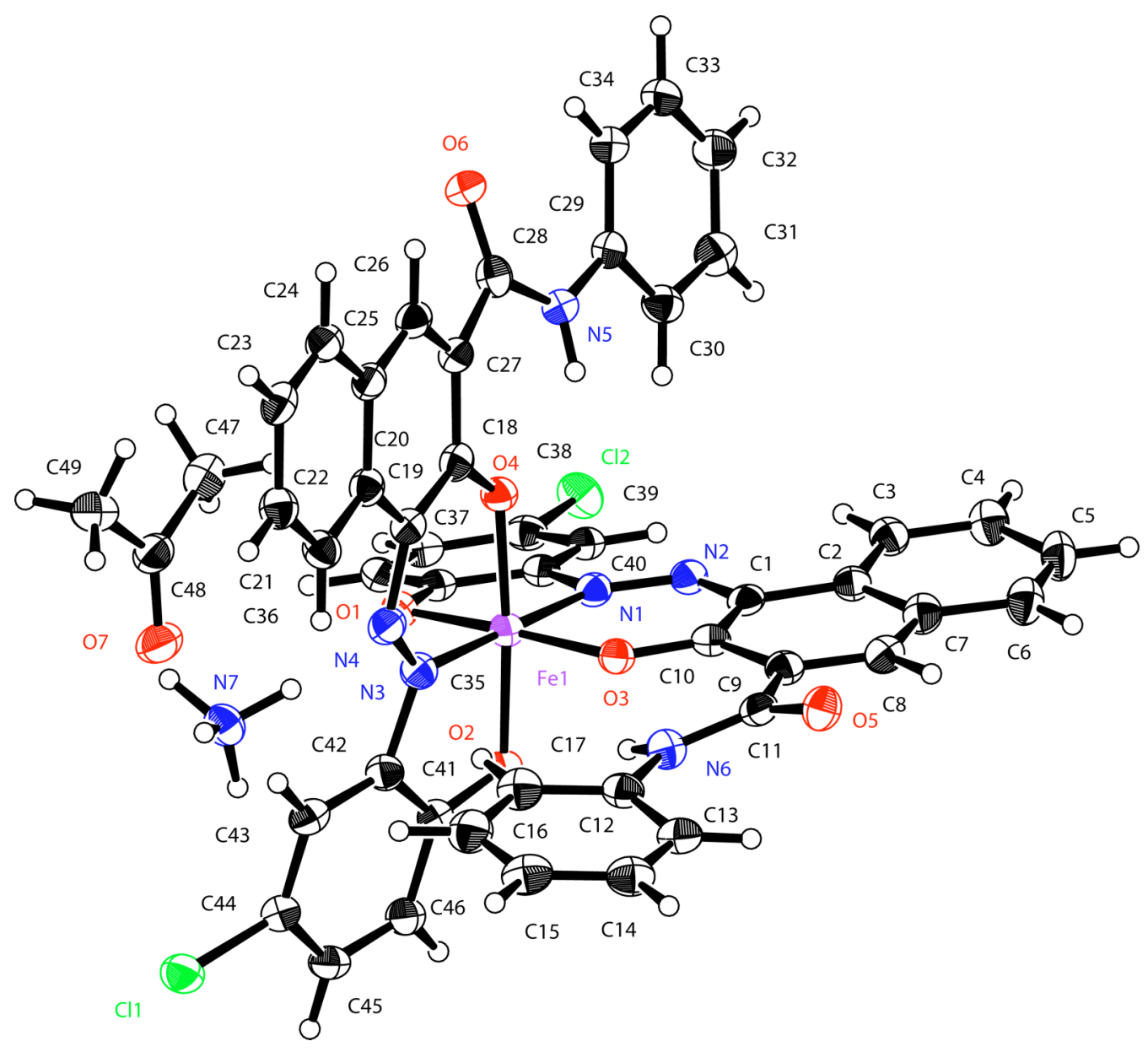

Figure 6. ORTEP plot of T-77/acetone.

lecular conformation is obviously different from that shown in Fig. 2(a), although the chemical formula with an inversion center has always been presented so far in the literature. $^{15}$ The correct scheme is shown in Fig. 2(b). Figure 6 shows the ORTEP plot of T-77/acetone. As in the case of $\mathrm{T}-77 /$ methanol, there is no inversion symmetry in the anion complex.

Figure 7(a) illustrates the packing arrangement of T-77/ methanol. Surprising to say, the $\mathrm{H}$ atoms of the ammonium cation are hydrogen bonded to $\mathrm{O} 1, \mathrm{O} 3^{\mathrm{i}}$ and $\mathrm{O} 6^{\mathrm{i}}$ of the anion complex (symmetry code: (i) $-1+x, y, z$ ) (i.e., bonded to two different anion complexes) as well as to $\mathrm{O} 7$ of methanol. Another intermolecular hydrogen bond is between $\mathrm{O} 7$ and O6 $^{\text {ii }}$ (symmetry code: (ii) $1-x, 1-y, 1-z$ ). The H-bond network described above links the metal complexes in chains running along the $a$ axis. A schematic picture is also given in Figure 7(b).

The molecular arrangement of T-77/acetone is strikingly different from that of T-77/methanol, especially in the network of H-bonds. Figures $8(\mathrm{a})$ and $8(\mathrm{~b})$ illustrate the packing arrangement. The ammonium cation shares its $\mathrm{H}$ atoms with the $\mathrm{O}$ atoms of the three different metal-anion complexes through $\mathrm{NH} \cdot \cdot \mathrm{O}$ hydrogen bonds and also with the $\mathrm{O}$ atom of the acetone molecule, again a $\mathrm{NH} \cdots \mathrm{O}$ hydrogen bond. On the other hand, in T-77/methanol, the ammonium cation shares its $\mathrm{H}$ atoms with two metal-anion com-

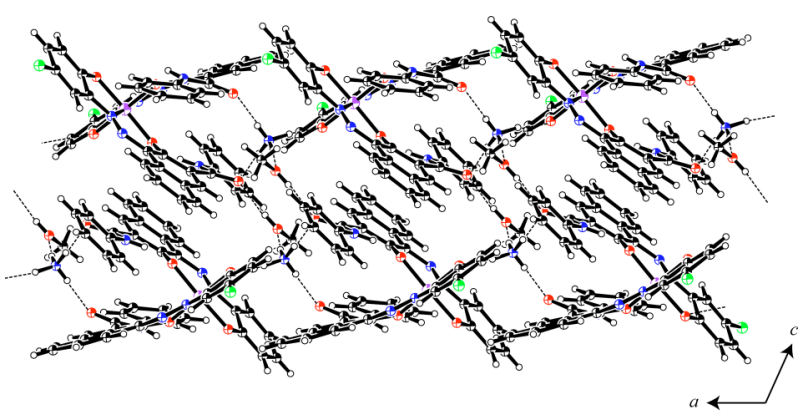

(a)

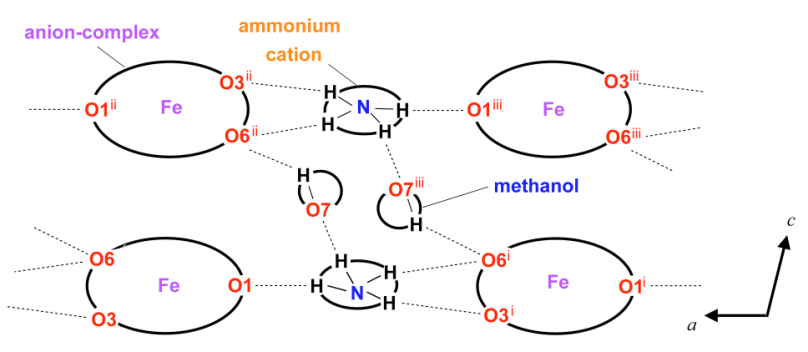

(b)

Figure 7. (a) Packing arrangement of T-77/methanol and (b) schematic 


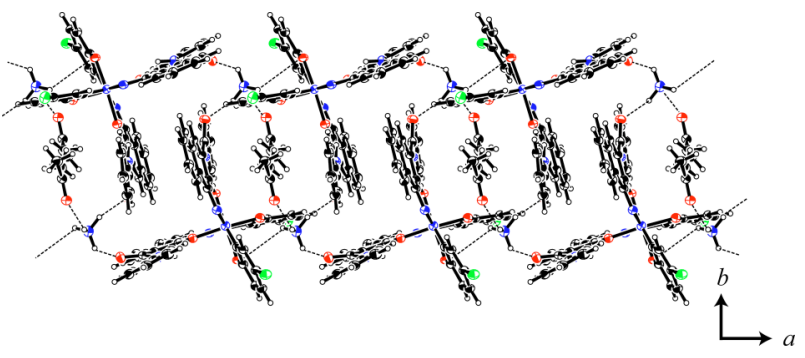

(a)
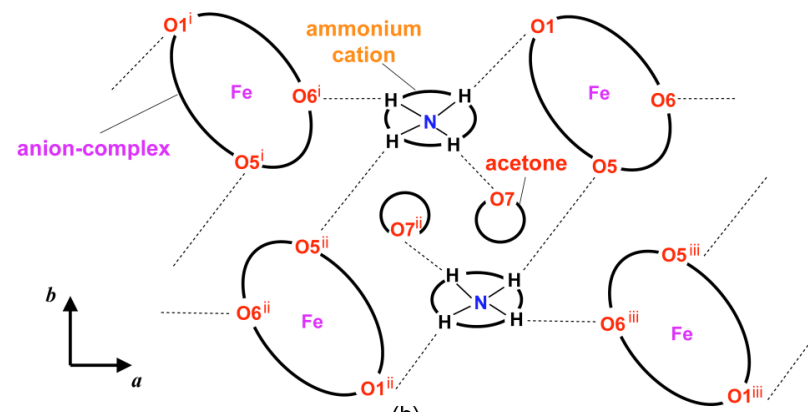

(b)

Figure 8. (a) Packing arrangement of T-77/acetone and (b) schematic.

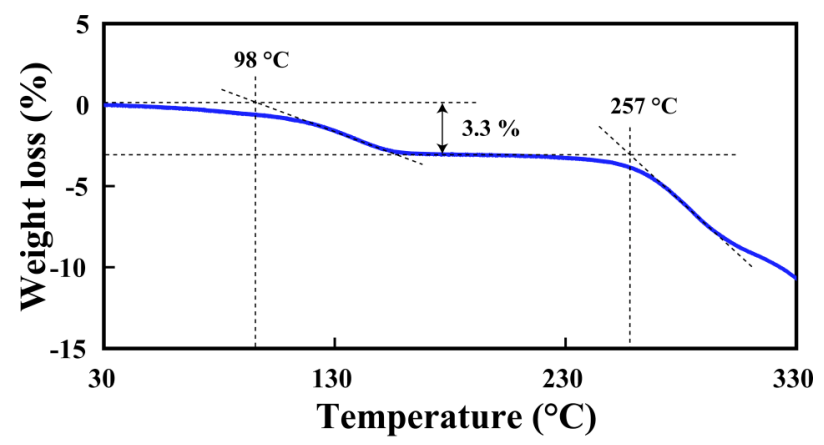

(a)

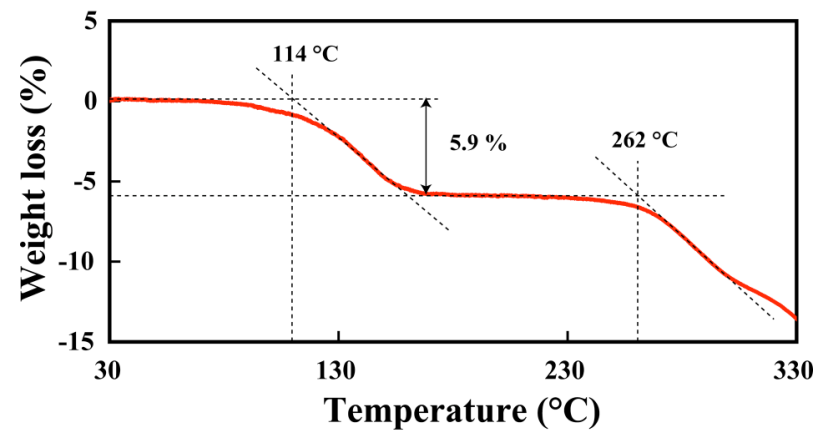

(b)

Figure 9. TGA curves for (a) T-77/methanol and (b) T-77/acetone.

plexes and one solvate molecule. Interestingly, the molecules are again assembled in chains that run along the $a$ axis.

It is important to note that it is the ammonium cation that bridges anion complexes (two in T-77/methanol and three in T-77/acetone). We have also confirmed by powder $\mathrm{x}$-ray diffraction analysis that the framework of the molecular arrangement remains mostly intact in both complexes

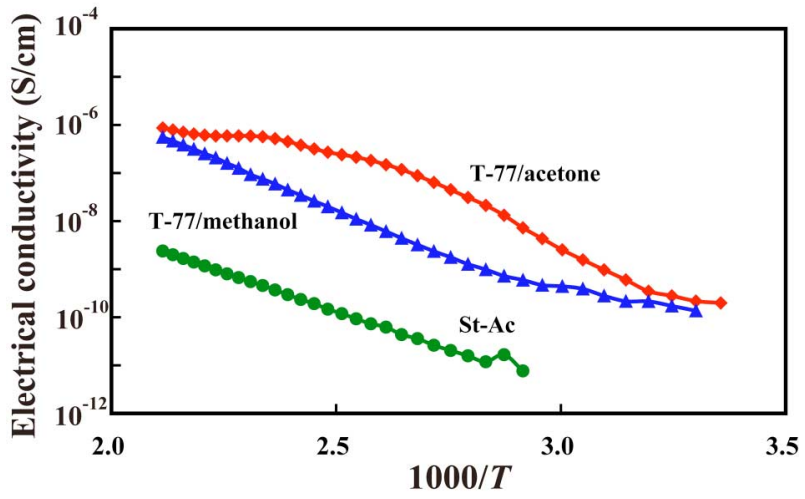

Figure 10. Temperature dependence of the electrical conductivity of T-77/methanol, T-77/acetone, and St-Ac.

even after desorption of the solvent molecules. Therefore, the difference in molecular arrangement between T-77/ methanol and T-77/acetone may lead to a different temperature dependence of the electrical conductivity, as discussed later.

TGA Measurements in Air

Figure 9(a) shows the TGA curve for T-77/methanol. The onset of the weight loss occurs around $98^{\circ} \mathrm{C}$, showing a weight loss of $3.3 \%$. This corresponds to one methanol molecule. On the other hand, the onset temperature of T-77/ acetone is $114^{\circ} \mathrm{C}$ and the weight loss amounts to $5.9 \%$ [Fig. 9(b)]. The present weight loss is due to desorption of one acetone molecule. In addition, the decomposition temperatures of both metal-anion complexes is rather high because of the hydrogen-bond network: $257^{\circ} \mathrm{C}$ in $\mathrm{T}-77 /$ methanol; $262^{\circ} \mathrm{C}$ in T-77/acetone.

It should be noted that the desorption and decomposition temperatures of T-77/acetone are higher than those of T-77/methanol. This is closely correlated to the strength of the intermolecular forces and is mainly attributed to the fact that the ammonium cation unites two different anion complexes in $\mathrm{T}-77 /$ methanol through $\mathrm{NH} \cdots \mathrm{O}$ hydrogen bonding, whereas the cation connects three anion complexes in T-77/acetone.

Temperature Dependence of the Electrical Conductivity Since azo-Fe complexes are regarded as organic semiconductors, the temperature dependence of the electrical conductivity is assumed to follow the Boltzmann distribution as given by

$$
n=n_{0} \exp \left(-E / k_{B} T\right)
$$

where $n, E, T$, and $k_{B}$ denote the number of carriers, the activation energy, the temperature, and the Boltzmann constant, respectively. Figure 10 shows the temperature dependence of the electrical conductivity (Arrhenius plot) for T-77/methanol, T-77/acetone, and a styrene-acrylic (St-Ac) resin, which is the main constituent of toners. A good linearity is observed in T-77/mechanol and St-Ac polymer, whereas the temperature dependence in T-77/acetone is characterized by a swell over the whole temperature range. 
The latter is presumably related to the acetone molecules included firmly in the lattice; these remain more tenaciously bound in this crystal.

The electrical conductivity of T-77/methanol at about $100^{\circ} \mathrm{C}$ is higher by two orders of magnitude than that at room temperature, and three orders of magnitude higher for T-77/acetone. In addition, the electrical conductivity of the St-Ac resin is lower than that of $\mathrm{T}-77 /$ methanol by more than two orders of magnitude. This indicates that T-77 with or without solvent molecules serves as a conductive channel between toner and carrier, while the electrical charge is expected to reside on the St-Ac polymer. This observed temperature dependence of the electrical conductivity supports our charge-control mechanism described in the Introduction.

\section{Conclusions to the First Part}

1. Two kinds of solvated azo-Fe complexes are isolated as single crystals. The space groups for T-77/methanol and T-77/acetone are $P \overline{1}$ and $P 2_{1} / n$, respectively.

2. In both azo-Fe complexes, pairs of the equivalent ligands lie cis to each other, showing that the anion complex has no inversion symmetry, although the chemical formula with inversion symmetry has always been presented in literature.

3. The ammonium cation bridges two metal-anion complexes in T-77/methanol through $\mathrm{NH} \cdots \mathrm{O}$ hydrogen bonding, whereas three anion complexes are held together in T-77/acetone. The present hydrogen-bond network is responsible for the high thermal stability of T-77.

4. The electrical conductivity of T-77/methanol at about $100^{\circ} \mathrm{C}$ is higher by two orders of magnitude than that at room temperature, while three orders of magnitude higher in T-77/acetone. The present temperature dependence supports our charge-control mechanism.

\section{Second Part-Thermal Stability of Sodium Salts of azo-Fe or azo-Cr Complexes}

As described in the preceding section, the thermal stability is due to the $\mathrm{NH} \cdots \mathrm{O}$ intermolecular hydrogen-bond network; that is, the hydrogen bond with a combination of a " $\mathrm{NH}_{4}{ }^{+}$/carbonyl $\mathrm{O}$ atom." Then, what happens when the $\mathrm{NH}_{4}{ }^{+}$is replaced by $\mathrm{Na}^{+}$[Fig. 3(a), designated as T-77Na] that has no hydrogen bonding ability; i.e., the combination of a $\mathrm{Na}^{+} /$carbonyl $\mathrm{O}$ atom? In this case, a coordination network between $\mathrm{Na}^{+}$and the carbonyl $\mathrm{O}$ is operative as described below. In the above two examples of T-77 and $\mathrm{T}-77 \mathrm{Na}$, the carbonyl $\mathrm{O}$ atom is common and included in the form of the moiety of naphthol AS as shown in Figs. 2(b) and 3(a). It is this carbonyl $\mathrm{O}$ atom that plays the crucial role for the formation of the hydrogen-bond or coordination network. Then, what happens again in the absence of the carbonyl $\mathrm{O}$ atom? This is the example of S-34Na as shown in Fig. 3(b), where the moiety of naphthol AS is replaced by $\beta$-naphthol. Our goal is to elucidate the origin of the thermal stability of these compounds from the structural point of view.
Table II. Crystallographic parameters for acetone or acetonitrile-solvated T-77Na.

\begin{tabular}{ccc}
\hline & T-77Na/acetone & T-77Na/acetonotrile ${ }^{17}$ \\
\hline Formula & {$\left[\mathrm{FeNa}\left(\mathrm{C}_{23} \mathrm{H}_{14} \mathrm{ClN}_{3} \mathrm{O}_{3}\right)_{2}\right.$} & {$\left[\mathrm{Fe}_{2} \mathrm{Na}_{2}\left(\mathrm{C}_{23} \mathrm{H}_{14} \mathrm{ClN}_{3} \mathrm{O}_{3}\right)_{4}\right.$} \\
$\left.\left(\mathrm{C}_{2} \mathrm{H}_{3} \mathrm{~N}\right)_{2}\left(\mathrm{H}_{2} \mathrm{O}\right)_{4}\right] 2 \mathrm{H}_{2} \mathrm{O}$ \\
Crystal system & $\left.\left(\mathrm{C}_{3} \mathrm{H}_{6} \mathrm{O}\right)_{2}\right]$ & Triclinic \\
Space group & Triclinic & $P \overline{-}$ \\
Molecular weight & $P\rceil^{-}$ & 2011.21 \\
$Z$ & 1026.64 & 1 \\
$a(\AA)$ & 2 & $11.4416(5)$ \\
$b(\AA)$ & $13.8165(4)$ & $14.1161(7)$ \\
$c(\AA)$ & $13.8623(4)$ & $15.0105(7)$ \\
$\alpha\left(\left(^{\circ}\right)\right.$ & $14.1524(5)$ & $72.396(1)$ \\
$\beta\left(\left(^{\circ}\right)\right.$ & $98.8179(10)$ & $76.2850(9)$ \\
$\gamma\left({ }^{\circ}\right)$ & $105.3882(12)$ & $83.015(1)$ \\
Density $\left(\mathrm{g} / \mathrm{cm}^{3}\right)$ & $109.0641(8)$ & 1.481 \\
$R$ & 1.431 & 0.086 \\
\hline
\end{tabular}

Crystallographic Parameters and Molecular Conformation of $\mathrm{T}-77 \mathrm{Na}$

Table II details the crystallographic parameters for acetone or acetonitrile-solvated azo-Fe complexes designated as T-77Na. ${ }^{16,17}$ Both compounds include solvent molecules: $\mathrm{T}-77 \mathrm{Na} / 2 \mathrm{CH}_{3} \mathrm{COCH}_{3}$ abbreviated to $\mathrm{T}-77 \mathrm{Na} /$ acetone and $\mathrm{T}-77 \mathrm{Na} / \mathrm{CH}_{3} \mathrm{CN}\left(\mathrm{H}_{2} \mathrm{O}\right)_{3}$ designated as $\mathrm{T}-77 \mathrm{Na} /$ acetonitrile for short.

Figure 11 shows the ORTEP plot of acetone-solvated $\mathrm{T}-77 \mathrm{Na}$ (i.e., $\mathrm{T}-77 \mathrm{Na}$ /acetone). There is no inversion symmetry in the anion complex, just as in the case of T-77/ acetone. Figure 12 shows the molecular arrangement of $\mathrm{T}-77 \mathrm{Na} /$ acetone. The sodium cation is found to form a dimer with another sodium atom as shown in Figure 13, where each sodium cation is coordinated by five ligands: three carbonyl oxygens of the three different anion complexes $\left(\mathrm{O} 5, \mathrm{O}^{\mathrm{i}}\right.$, and $\left.\mathrm{O}^{\mathrm{ii}}\right)$ (symmetry code: (i) $-x, 1-y$, $1-z$; (ii) $1-x, 1-y, 1-z$ ) and two acetone molecules (O7 and O8). Surprising to say, each sodium cation unites three different anion complexes through the carbonyl oxygen atoms: $\mathrm{O} 5, \mathrm{O}^{\mathrm{i}}$, and $\mathrm{O}^{\mathrm{ii}}$. This indicates that anion complexes form a two-dimensional network parallel to the $a$ axis. Figure 14 shows the schematic illustration of the crystal structure of $\mathrm{T}-77 \mathrm{Na} /$ acetone.

On the other hand, in acetonitrile-solvated T-77Na (i.e., $\mathrm{T}-77 \mathrm{Na}$ /acetonitrile), the situation of the sodium coordination is quite different. Figure 15 shows the ORTEP plot of the anion complex dimer in T-77Na/acetonitrile. The sodium cation bridges two different anion complexes to form an anion complex dimer as shown in Figure 16. This dimerization contributes to the stabilization of $\mathrm{T}-77 \mathrm{Na} /$ acetonitrile.

In summary, the sodium cation plays a decisive role in bridging anion complexes in both $\mathrm{T}-77 \mathrm{Na} /$ acetone and $\mathrm{T}-77 \mathrm{Na}$ /acetonitrile crystals, leading to a high thermal stability of these compounds. 


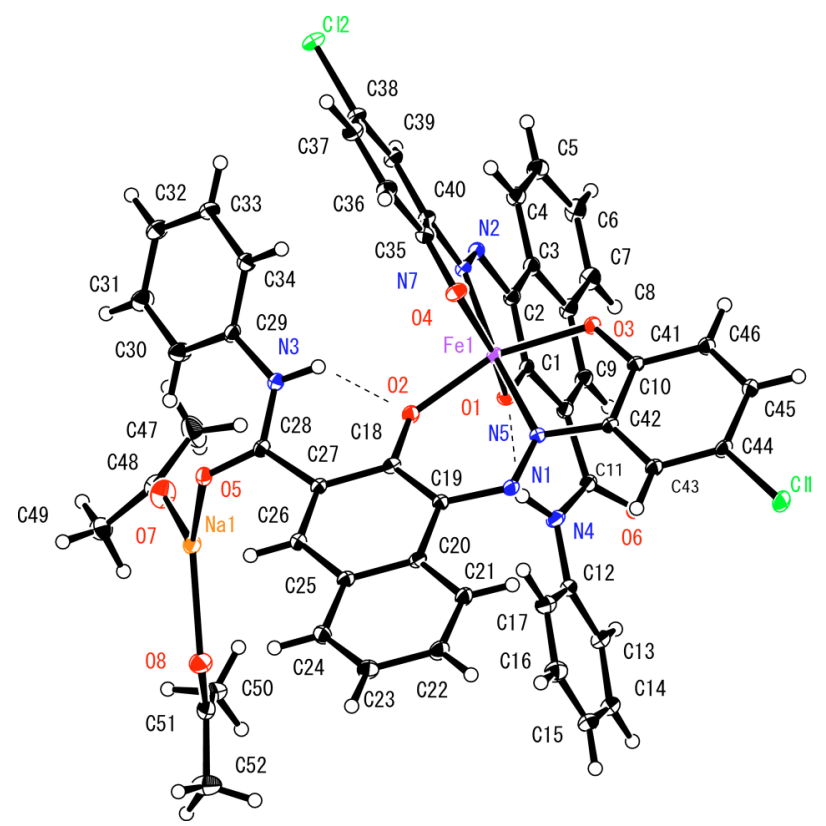

Figure 11. ORTEP plot of T-77 Na/acetone.

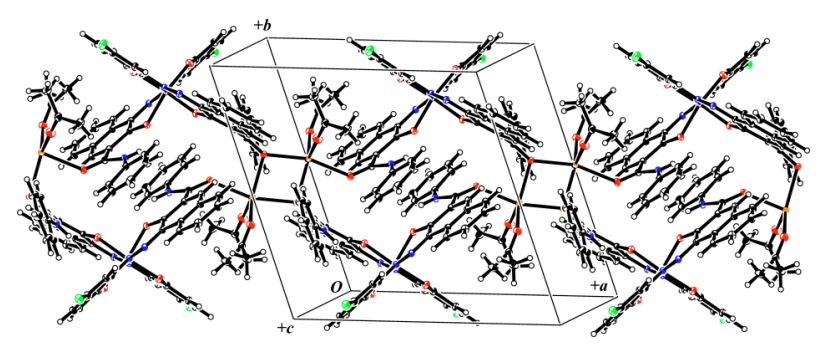

Figure 12. Packing arrangement of $\mathrm{T}-77 \mathrm{Na}$ /acetone.

Crystallographic Parameters and Molecular Conformation of $\mathrm{S}-34 \mathrm{Na}$

Table III details the crystallographic parameters for the acetone-solvated azo-Cr complex (S-34Na/acetone). ${ }^{18}$ This compound includes two acetone molecules: $\mathrm{S}-34 \mathrm{Na} / 2 \mathrm{CH}_{3} \mathrm{COCH}_{3}$. S-34Na is a dinuclear complex of octahedral $\mathrm{Cr}^{\mathrm{III}}$ and $\mathrm{Na}^{\mathrm{I}}$ units and is found to form a onedimensional polymer running along the $c$ axis.

Figure 17 shows the ORTEP plot of S-34Na. The unit is composed of an octahedral $\mathrm{Cr}^{\mathrm{III}}$ unit and an octahedral $\mathrm{Na}^{\mathrm{I}}$ one. The anion complex exists in cis-form, just as in the ordinary azo-Fe complexes previously reported. ${ }^{13,14,16,17}$ Each $\mathrm{Cr}^{\mathrm{III}}$ atom is chelated by the $\mathrm{N}$ and two $\mathrm{O}$ atoms from two [(5-chloro-2-oxidophenyl)diazenyl $]$-2-naphtholate ligands. On the other hand, the $\mathrm{Na}^{\mathrm{I}}$ cation coordinates to a phenoxy $\mathrm{O}$ atom from the two ligands of each octahedral $\mathrm{Cr}^{\mathrm{III}}$ unit, a naphthoxy $\mathrm{O}$ atom from the two ligands of each neighboring $\mathrm{Cr}^{\mathrm{III}}$ unit, and two acetone molecules. The octahedral $\mathrm{Cr}^{\mathrm{III}}$ unit and the octahedral $\mathrm{Na}^{\mathrm{I}}$ one are repeated alternately to form a one-dimensional polymer along the $c$ axis through the four $\mathrm{O}$ ligands in common. The polymer formation contributes to a significant stabilization of S-34Na whose property is a prerequisite for its CCA application in electrophotography. Figure 18 is the schematic of the

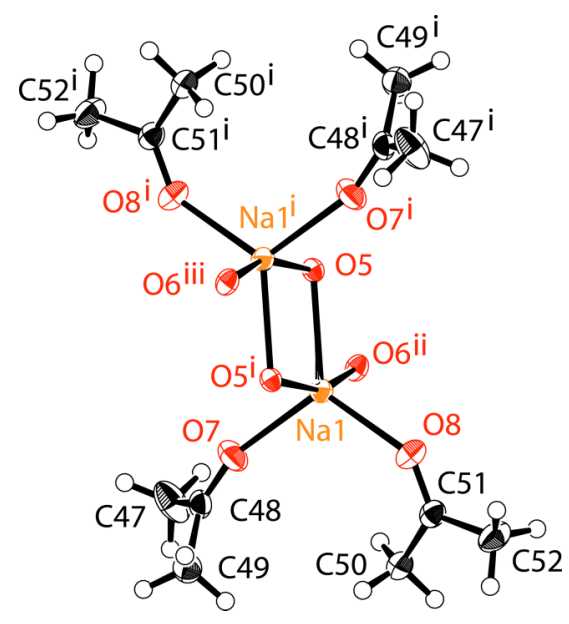

Figure 13. The sodium cation dimer with four acetone molecules. [Symmetry code: (i) $-x, 1-y, 1-z$; (ii) $1-x, 1-y, 1-z$; (iii) $-1+x, y, z]$.

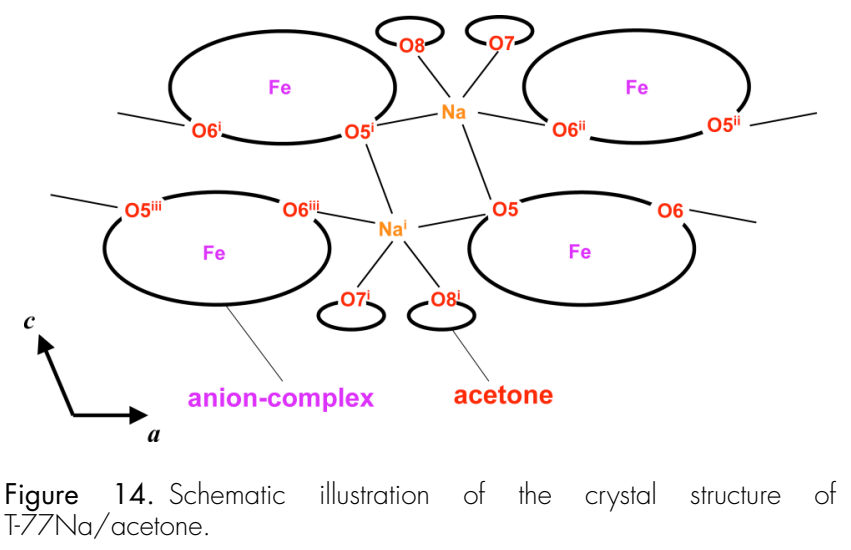

dinuclear complex of octahedral $\mathrm{Cr}^{\mathrm{III}}$ and $\mathrm{Na}^{\mathrm{I}}$ units and this forms a one-dimensional polymer running along the $c$ axis.

TGA Measurements of $\mathrm{T}-77 \mathrm{Na}$ and $\mathrm{S}-34 \mathrm{Na}$

Figure 19 shows the TGA curve for T-77Na/acetone. The weight loss in T-77Na/acetone occurs in two steps at about $137^{\circ} \mathrm{C}$ (weight loss: $6.44 \%$ ) and at about $204^{\circ} \mathrm{C}$ (weight loss: $4.81 \%$ ). The total weight loss of $11.25 \%$ corresponds to two acetone molecules. Then, decomposition occurs at about $307^{\circ} \mathrm{C}$. The present high decomposition point is obviously due to the coordination network caused by sodium cations. S-34Na behaves nearly the same way as $\mathrm{T}-77 \mathrm{Na} /$ acetone. Figure 20 shows the TGA curve for S-34Na/acetone. The onset of the weight loss occurs around $187^{\circ} \mathrm{C}$, showing a weight loss of $13.89 \%$. This corresponds to two acetone molecules. Finally, the decomposition takes place around $333^{\circ} \mathrm{C}$, which is extremely high for ordinary metal complexes. The present high thermal stability is obviously due to the polymer formation of S-34Na.

\section{Conclusions to the Second Part}

1. The sodium cation in $\mathrm{T}-77 \mathrm{Na}$ is coordinated by five ligands: carbonyl $\mathrm{O}$ atoms of the anion complex plus $\mathrm{O}$ atoms of solvent molecules. The $\mathrm{Na}$ cation plays a decisive role in bridging anion complexes in both $\mathrm{T}-77 \mathrm{Na}$ /acetone and $\mathrm{T}-77 \mathrm{Na}$ /acetonitrile, leading to a high thermal stability for these compounds. 


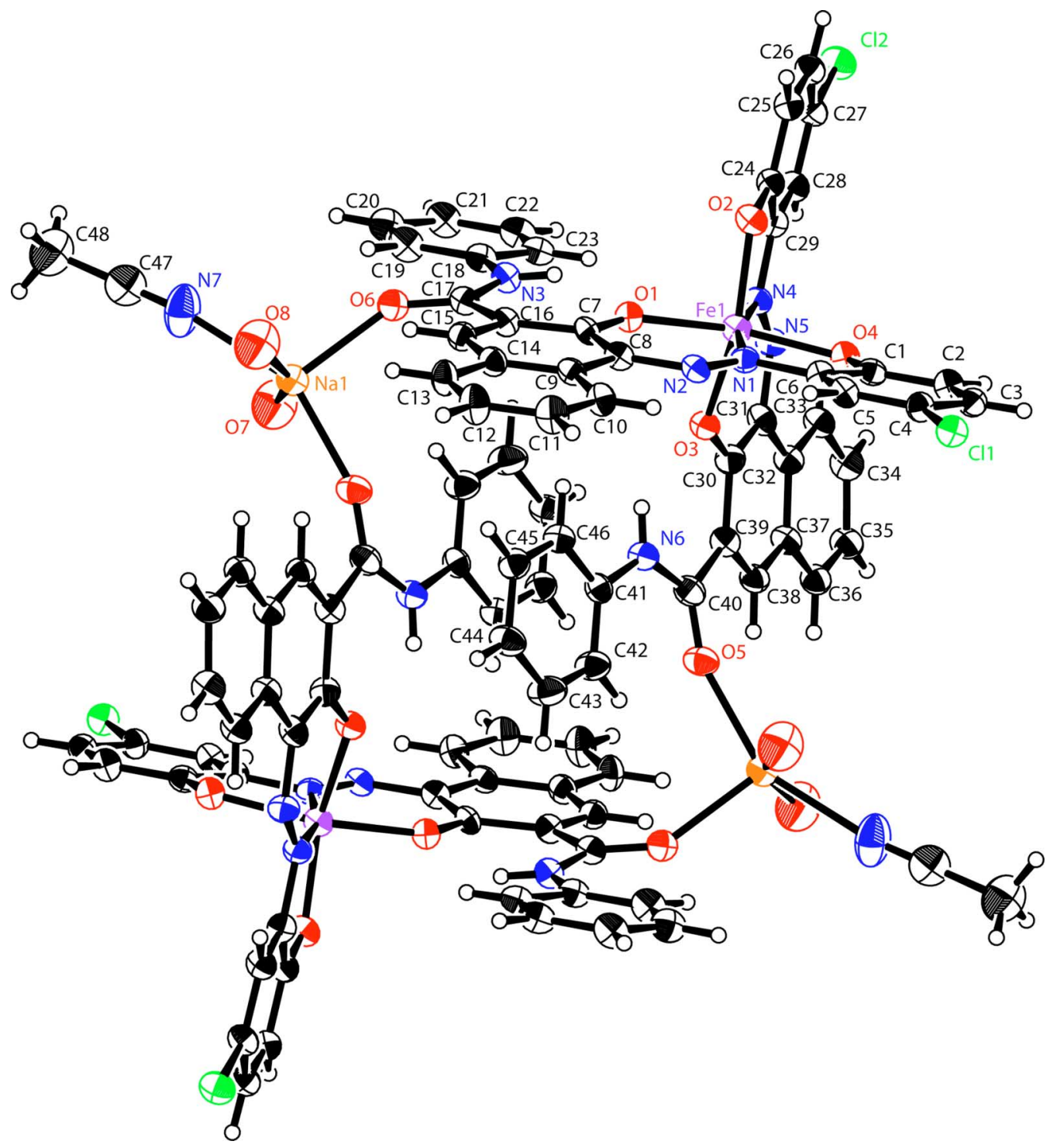

Figure 15. ORTEP plot of the anion complex dimer in T-77 Na/acetonitrile.

2. The high-decomposition temperature of $\mathrm{T}-77 \mathrm{Na} /$ acetone and $\mathrm{T}-77 \mathrm{Na} /$ acetonitrile is due to a sheetlike coordination network established by sodium cations.

3. S-34Na is a dinuclear complex of octahedral $\mathrm{Cr}^{\mathrm{III}}$ and $\mathrm{Na}^{\mathrm{I}}$ units.

4. The octahedral $\mathrm{Cr}^{\mathrm{III}}$ unit and the octahedral $\mathrm{Na}^{\mathrm{I}}$ one are repeated alternately to form a one-dimensional polymer along $c$ through the four $\mathrm{O}$ ligands in common. This greatly contributes to the thermal stability.

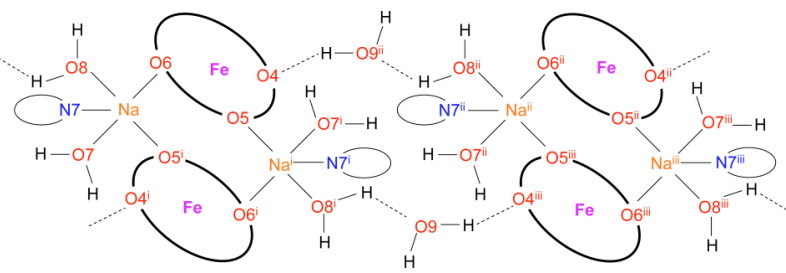

Figure 16. Schematic illustration of the formation of the hydrogen-bond network through two water molecules.
Table III. Crystallographic Parameters for S-34Na/acetone.

\begin{tabular}{cc}
\hline & S-34Na/acetone ${ }^{18}$ \\
\hline Formula & $\mathrm{C}_{32} \mathrm{H}_{18} \mathrm{Cl}_{2} \mathrm{CrNaN}_{4} \mathrm{O}_{4}$ \\
& $/ 2 \mathrm{CH}_{3} \mathrm{COCH}_{3}$ \\
Crystal system & Orthorhombic \\
Space group & Pnna \\
Molecular weight & 784.55 \\
$Z$ & 4 \\
$a(\AA)$ & $18.5082(17)$ \\
$b(\AA)$ & $26.199(3)$ \\
$c(\AA)$ & $7.1726(6)$ \\
Density $\left(\mathrm{g} / \mathrm{cm}^{3}\right)$ & 1.498 \\
$R$ & 0.110 \\
\hline
\end{tabular}




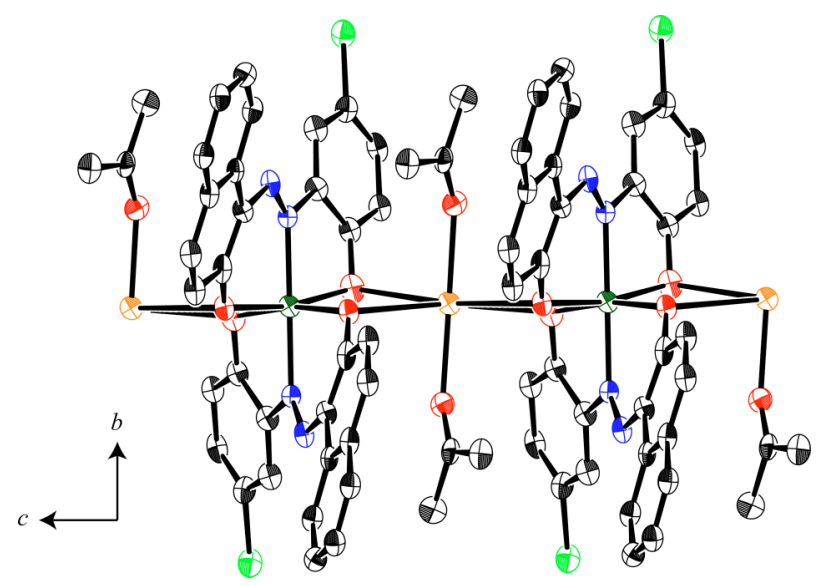

Figure 17. ORTEP plot of S-34Na/acetone.

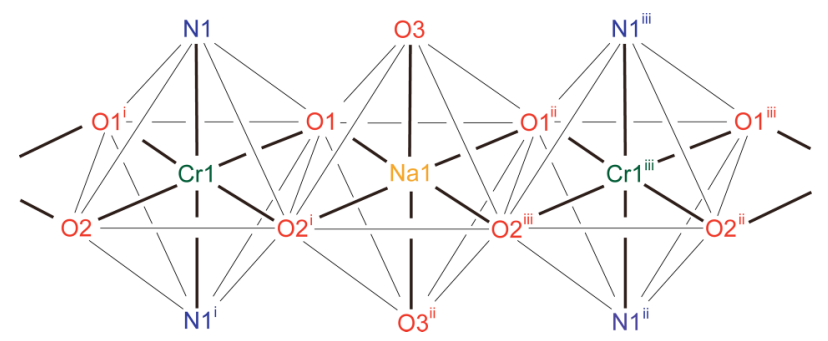

Figure 18. Schematic illustration of the dinuclear complex of octahedral $\mathrm{Cr}$ 'll and $\mathrm{Na}^{\prime}$ units and this forms a one-dimensional polymer running along the $c$ axis.

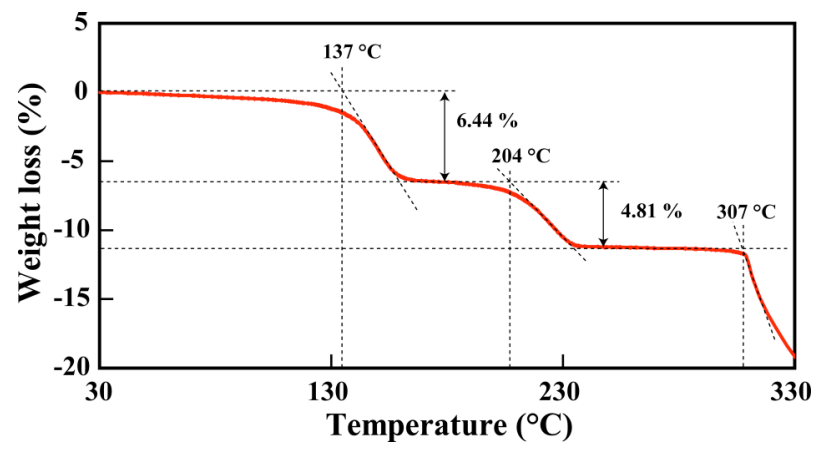

Figure 19. TGA curve for T-77 Na/acetone.

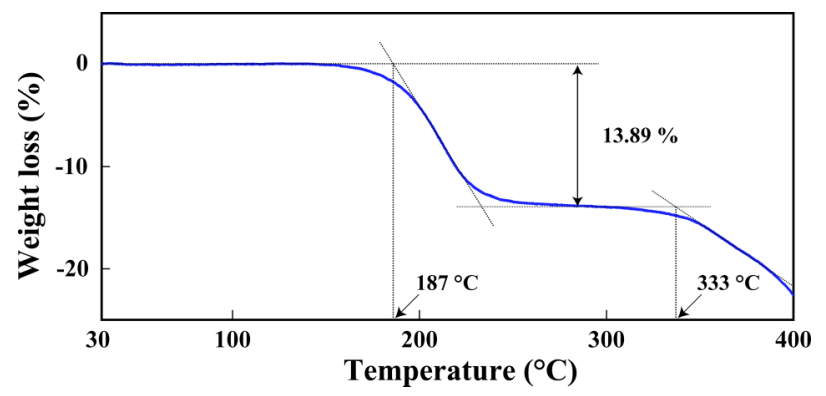

Figure 20. TGA curve for S-34Na/acetone.

\section{REFERENCES}

${ }^{1} \mathrm{H}$. Zollinger, Color Chemistry-Syntheses, Properties, and Applications of Organic Dyes and Pigments, 3rd revised ed. (VHCH, Zürich and Wiley-VCH, Weinheim, 2003), pp. 206-220.

${ }^{2}$ L. B. Schein, "Theory of toner charging," J. Imaging Sci. Technol. 37, 1-4 (1993).

${ }^{3}$ L. B. Schein, "Electric field theory of toner charging," J. Imaging Sci. Technol. 44, 475-483 (2001).

${ }^{4}$ R. J. Nash, M. L. Grande, and R. N. Muller, "CCA effects on the triboelectric charging properties of a two-component xerographic developer," Proc. IS\&T’s NIP17 (IS\&T, Springfield. VA, 2001) pp. 358-364.

${ }^{5}$ A. Suka, M. Takeuchi, K. Suganami, and T. Oguchi, "Toner charge generated by CCA particles at the interface between toner and carrier," J. Imag. Soc. Jpn. 45, 127-132 (2006).

${ }^{6}$ J. Guay, J. E. Ayala, and A. F. Diaz, "The question of solid-state electron transfer in contact charging between metal and organic materials," Chem. Mater. 3, 1068-1073 (1991).

${ }^{7}$ J. Mizuguchi, A. Hitachi, Y. Sato, and K. Uta, "Study of the charge control mechanism of charge control agents," J. Imaging Sci. Technol. 52, 030506 (2008).

${ }^{8}$ J. Mizuguchi, K. Hino, and K. Tojo, "Strikingly different electronic spectra of structurally similar perylene imide compounds," Dyes Pigm. 70, 126-135 (2006).

${ }^{9}$ M. Okubo, H. Nanami, and I. Kasahara, "Toners for electrostac images," Jpn. Pat. 2000-47433 (2000).

${ }^{10}$ M. Yasumatsu, K. Kuroda, O. Yamate, K. Sato, A. Hikata, and H. Yushina, "Charge control agents and CCA-containing toners for electrostatic images” Jpn. Pat. 2006-113576 (2006).

${ }^{11}$ M. C. Burla, R. Caliandro, M. Camalli, B. Carrozzini, G. L. Cascarano, L. De Caro, C. Giacovazzo, G. Polidori, and P. Spagna, "SIR2004: An improved tool for crystal structure determination and refinement," J. Appl. Crystallogr. 38, 381-388 (2005).

${ }^{12}$ G. M. Sheldrick, "A short history of SHELX," Acta Crystallogr., Sect. A: Found. Crystallogr. A64, 112-122 (2008).

${ }^{13} \mathrm{~J}$. Mizuguchi, Y. Sato, and K. Uta, "Ammonium bis\{3-anilinocarbonyl-1[(5-chloro-2-oxidophenyl)diazenyl]-2-naphtholato\}ferrate(III) methanol solvate," Acta Crystallogr., Sect. E: Struct. Rep. Online E63, m1327-m1328 (2007).

${ }^{14}$ J. Mizuguchi, K. Uta, and Y. Sato, “Ammonium bis\{3-anilinocarbonyl-1[(5-chloro-2-oxidophenyl)diazenyl]-2-naphtholato\}ferrate(III) acetone solvate," Acta Crystallogr., Sect. E: Struct. Rep. Online E63, m1329-m1330 (2007).

${ }^{15}$ For example, K. Tanaka, "Triboelectric charge control for toner," J. Electrost. 19, 15-21 (1995).

${ }^{16}$ J. Mizuguchi, Y. Sato, and K. Uta, "Poly[bis(acetone)bis $[\mu-4-$ [(5-chloro-2-oxidophenyl)diazenyl]-3-oxido- $N$-phenylnaphthalene2-carboxamidato]sodium(I)ferrate(III)]," Acta Crystallogr., Sect. E: Struct. Rep. Online E63, m1377-m1378 (2007).

${ }^{17}$ Y. Sato, K. Uta, and J. Mizuguchi, "Diacetonitriletetrakis $\left\{\mu_{2}-3\right.$-anilinocarbonyl-1-[(5-chloro-2-oxidophenyl)diazenyl]2-naphtholato\}tetraquadiiron(III)disodium(I) dihydrate," Acta Crystallogr., Sect. E: Struct. Rep. Online E64, m240-m241 (2008).

${ }^{18} \mathrm{~S}$. Ito, Y. Sato, and J. Mizuguchi, "Poly[bis (acetone- $\left.\kappa O\right)$ bis $\left\{\mu_{3}-1\right.$ - [(5-chloro-2-oxidophenyl)diazenyl]-2-naphtholato$\left.\kappa^{4} O: O, O^{\prime}: O^{\prime}\right\}$ sodium(I)chromium(III)]," Acta Crystallogr., Sect. E: Struct. Rep. Online E64, m333-m334 (2008). 
(C)2009 Society for Imaging Science and Technology (IS\&T)

All rights reserved. This paper, or parts thereof, may not be reproduced in any form without the written permission of IS\&T, the sole copyright owner of The Journal of Imaging Science and Technology.

For information on reprints or reproduction contact

Donna Smith

Production Editor

The Journal of Imaging Science and Technology

Society for Imaging Science and Technology

7003 Kilworth Lane

Springfield, Virginia 22151 USA

703/642-9090 extension 107

703/642-9094 (fax)

dsmith@imaging.org

www.imaging.org 